Gut, 1987, 28, 255-259

\title{
Comparative modes of action of lactitol and lactulose in the treatment of hepatic encephalopathy
}

\author{
D H PATIL, D WESTABY, Y R MAHIDA, K R PALMER, R REES, \\ M L CLARK, A M DAWSON, AND D B A SILK \\ From the Department of Gastroenterology and Nutrition, Central Middlesex Hospital, London, and \\ Department of Gastroenterology, St Bartholomew's Hospital, London
}

SUMmARY Lactitol, an unabsorbed sugar with defined laxative threshold and superior taste properties has been suggested as an alternative to lactulose in the treatment of hepatic encephalopathy. In the present study we have compared the colonic metabolism of the two sugars using an in vitro faecal incubation system. Both sugars were readily metabolised by faecal bacteria producing volatile fatty acids and the metabolism was inhibited by neomycin. The effect of lactitol and lactulose on terminal ileal and colonic $\mathrm{pH}$ was monitored in six normal subjects using a radiotelemetry technique. Both sugars significantly lowered right colonic $\mathrm{pH}$ (basal $-6 \cdot 51 \pm 0 \cdot 48 \mathrm{vs}$ lactitol $-5 \cdot 63 \pm 0 \cdot 50$; lactulose $-5 \cdot 18 \pm 0 \cdot 82, \mathrm{p}<0 \cdot 05)$. The $\mathrm{pH}$ of rest of the colon and terminal ileum was unaffected. Neomycin given concurrently with lactulose abolished acidification of right colon. As lactitol and lactulose have similar effects within the colon, lactitol would appear to have a role in the treatment of hepatic encephalopathy. As neomycin antagonises the effect of lactulose in the colon, its concurrent use may be less effective in the treatment of hepatic encephalopathy.

Lactulose, an unabsorbed disaccharide (1:4, Bgalactosido-fructose) has been extensively used in the treatment of hepatic encephalopathy. ${ }^{12}$ Lactulose, however, is excessively sweet and consequently is unacceptable to some patients. Lactitol (Bgalactosido-sorbitol), a disaccharide analogue of lactulose has recently been described. ${ }^{3}$ This sugar is highly water soluble, less sweet than lactulose and is not absorbed in the human small intestine. ${ }^{+}$It has seemed to us therefore that lactitol might have a potential as an alternative therapeutic agent to lactulose in the treatment of hepatic encephalopathy. A recent open clinical trial' supports this suggestion as lactitol appeared to be as effective as lactulose in the management of patients with this condition.

In the present study experiments were designed to characterise the colonic metabolism of lactitol. In the first, an in vitro faecal incubation system was developed to simulate anaerobic fermentation of lactitol by human faecal bacteria. In the second, the

Address for correspondence: Dr D H Patil. Dept of Gastroenterology \& Nutrition. (entral Middlesex Hospital, London NW10 7NS

Received for publication 3 July 1986 effects of lactulose and lactitol on ileal and colonic $\mathrm{pH}$ in vivo were compared using a radiotelemetry device in normal human subjects.

The combination of neomycin and lactulose is still used in the treatment of hepatic encephalopathy despite the theoretical possibility that neomycin may inhibit the bacterial metabolism of lactulose. We have therefore taken the opportunity of investigating the effect of neomycin on colonic lactulose metabolism in vitro and in vivo.

\section{Methods}

COLONIC BACTERIAL METABOLISM OF LACTITOL IN VITRO

An in vitro culture system was developed to simulate as closely as possible the anaerobic metabolism of human colonic bacterial flora in vivo. A glass reservoir painted black externally to exclude light was used as the reaction chamber. Normal human volunteers passed approximately $25 \mathrm{~g}$ faeces into a beaker containing degassed water. The stool was immediately mixed with $500 \mathrm{ml}$ nutrient medium in the reaction chamber which contained, $\mathrm{NaCl} 68$ 
$\mathrm{mmol} / \mathrm{l} ; \mathrm{KCl} 5 \mathrm{mmol} / \mathrm{l}$, a free L-amino acid mixture $(0.47 \mathrm{mg}$ amino acid nitrogen/l, Vamin N Kabivitrum Ltd), sodium taurocholate $10 \mathrm{mmol} / \mathrm{l}$ to inhibit growth of non-colonic bacteria and either lactitol or lactulose $20 \mathrm{~g} / \mathrm{l}$. The reaction mixture was stirred continuously and maintained at $37^{\circ} \mathrm{C}$. The surface of the mixture was continuously flushed with $\mathrm{O}_{2}$ free $\mathrm{N}_{2}$ to maintain anaerobicity. The colonic mucosa in vivo normally secretes $\mathrm{HCO}_{3}$ ions" whereby the intraluminal $\mathrm{pH}$ of colon is maintained in the range of 6-7.7 In the present system the $\mathrm{pH}$ of reaction mixture was maintained at 7.0 by continuous titration of $1 \mathrm{M} / 1$ $\mathrm{NaOH}$ using an autoburette (Radiometer, Copenhagen, Denmark).

In pilot studies, aliquots of freshly passed faeces and reaction mixture were cultured after 24 hour incubation. Cultures from the reaction mixtures showed the presence of both aerobic and anaerobic organisms representative of those cultured from aliquots obtained from the same faecal samples before incubation.

Aliquots of samples $(20 \mathrm{ml})$ were collected from the reaction chamber at 0 and $24 \mathrm{~h}$ incubation into a universal container maintained at $4^{\circ} \mathrm{C}$, which was then immediately frozen and stored at $-20^{\circ} \mathrm{C}$ until analysis of volatile fatty acids was carried out.

\section{EXPERIMENTAL DESIGN}

Stool samples from five normal human subjects were incubated with the lactitol containing medium, and separate stool samples from the same subjects incubated with lactulose containing medium. In three further experiments, stool samples were incubated with the lactulose containing medium and after establishing that bacterial fermentation was proceeding, as evidenced by titration requirements of $\mathrm{NaOH}$ to maintain $\mathrm{pH}$ at $7 \cdot 0$, neomycin was added in doses of 100,300 , and $500 \mathrm{mg}$ respectively and incubation carried out for 24 hours as described above.

ANALYTICAL TECHNIQUE

The volatile fatty acid levels in the culture medium were measured by a modified gas liquid chromatography method as previously described. ${ }^{x}$ The chromatograph used was a Pye Unicam 104 with a flame ionisation detector. Samples of the culture medium $(1 \mathrm{ml})$ were mixed with $0 \cdot 1 \mathrm{ml}$ of concentrated $\mathrm{HCl}$ and $0.2 \mathrm{ml} 50 \mathrm{mmol} / 13$-methyl valeric acid (internal standard). The mixture was centrifuged and the supernatant $(2 \mathrm{ul})$ injected into a column of $5 \%$ poly neopentyl glycol sebacate, $1 \%$ phosphoric acid and Anakrom A (80-100 mesh) packed in a $1.8 \times$ $0.002 \mathrm{~m}$ glass column (Field Instruments Co Ltd, Weybridge, Surrey) maintained at $110^{\circ} \mathrm{C}$.

Standard curves were constructed by injecting calibrated amounts of a mixture of each volatile fatty acid and samples quantified from peak height measurement.

Lactic acid was measured as previously described" with a standard lactate dehydrogenase kit (Boehringer Mannheim Ltd, London).

EFFECT OF LACTULOSE AND LACTITOL ON TERMINAL ILEAL AND COLONIC $\mathrm{pH}$

Six healthy volunteers all members of the department gave their informed consent and participated in a randomised crossover study. The study was approved by the Ethical Committee of Brent Area Health Authority. pH sensitive radiotelemetry capsules (Remote Control Systems Ltd, London) were calibrated in standard buffer solutions at $37^{\circ} \mathrm{C}$ and then swallowed. The capsules were allowed to pass through the intestine and $\mathrm{pH}$ recordings were obtained for five to 10 minute periods every one to two hours. The full details of the technique used to measure intraluminal $\mathrm{pH}$ by radiotelemetry have been described previously." Initially the site of capsule was determined by occasional radiographic screening. In later studies we found that the capsule could be satisfactorily localised by identifying the site of maximum signal strength and then following the $\mathrm{pH}$ changes along its course. The capsule remained in the caecum for six to 24 hours and the passage of capsule from terminal ileum into caecum was characterised by a sudden and sustained fall in $\mathrm{pH}$ which enabled us to identify its entry from terminal ileum into the caecum. Mean values of repeated measurements of $\mathrm{pH}$ from terminal ileum, right colon, left colon and rectum were obtained. The rectum was identified by noting maximum signal strength on the lower sacrum or by recording the $\mathrm{pH}$ just before the capsule was passed. In only one study which was abandoned the $\mathrm{pH}$ capsule remained in the right colon for more than 36 hours. In all other studies it was possible to obtain the $\mathrm{pH}$ measurements in the terminal ileum, right colon, left colon, and rectum. In majority of cases the $\mathrm{pH}$ of freshly passed stool was also measured.

EXPERIMENTAL DESIGN

The subjects were randomly assigned to receive a normal diet, or this supplemented with lactulose and lactitol. Both sugars were consumed for three to four days in increasing doses so as to produce two to three semiformed motions $/ 24 \mathrm{~h}$. The final doses of lactulose and lactitol administered were $30-80 \mathrm{~g} / 24 \mathrm{~h}$ and $40-18() \mathrm{g} / 24 \mathrm{~h}$ in two to four divided daily doses. All subjects undertook normal daily activities and each study period was separated by at least seven days to allow normalisation of colonic bacterial flora and bowel habit.

In three of the subjects, the lactulose study was 
repeated as described except that neomycin at a dose of 0.5 to $1.0 \mathrm{~g}$ three to four times a day was also administered.

STATISTICAL ANALYSIS

The statistical differences of intraluminal $\mathrm{pH}$ changes were assessed using the paired $t$ test.

\section{Results}

I COLONIC BACTERIAL METABOLISM OF

I. ACTITOL. AND LACTULOSE IN VITRO

The titration requirement of $\mathrm{NaOH}$ to maintain $\mathrm{pH}$ $7 \cdot()$ during lactitol incubation was $103+33 \mathrm{mmol} / 24 \mathrm{~h}$ $($ mean $+\mathrm{SD} ; \mathrm{n}=5)$ and $152+22 \mathrm{mmol} / 24 \mathrm{~h}$ during lactulose incubation. The volatile fatty acids identified during both incubation studies were acetic acid, propionic acid, butyric acid, and lactic acid. The concentrations of volatile fatty acids liberated during the 24 hour incubation period are summarised in Table 1.

When neomycin at doses of 100 and $300 \mathrm{mg}$ was added to lactulose containing medium, the titration requirements were 140 and $130 \mathrm{mmol} \mathrm{NaOH} / 24 \mathrm{~h}$. At a dose of $500 \mathrm{mg}$ however, lactulose metabolism appeared almost completely inhibited for 24 hours and the reaction had a titration requirement of only $10 \mathrm{mmol} \mathrm{NaOH} / 24 \mathrm{~h}$.

2 EFFECT OF I.ACTITOL. AND LACTULOSE ON TERMINAL ILEAL AND COLONIC PH

In the control experiments there was a significant fall in $\mathrm{pH}$ between the terminal ileum $(7 \cdot 5 \mathrm{I}+(0 \cdot 37)$ and right colon $(6 \cdot 51+(0 \cdot 48 ; \mathrm{p}<() \cdot 01)$. The $\mathrm{pH}$ values found in the right colon, left colon and rectum were similar to those previously described ${ }^{\top}$ and are shown in Table 2.

There was a significant fall in right colonic $\mathrm{pH}$ during ingestion of lactitol to $5 \cdot 63+() \cdot 54(p<0 \cdot() 5)$ and lactulose to $5 \cdot 18+() \cdot 82(\mathrm{p}<0 \cdot() 1)$. The values obtained during the ingestion of the two sugars were, however, not significantly different. Neither sugar had a significant effect on the luminal $\mathrm{pH}$ of the terminal ileum, left colon or the faeces.

When lactulose was administered with neomycin, the $\mathrm{pH}$ profile of the terminal ileum, right colon, left colon, rectum and faeces as shown in Table 2 were not significantly different from those recorded during the control experiments.

\section{Discussion}

Lactitol is produced by hydrogenation of lactose and should soon be available as a pure, crystalline powder which is highly soluble in water. With a sweetness of $35 \%$ compared with sucrose, its taste properties are considerably superior to its analogue lactulose. Recent intestinal perfusion experiments have shown that lactitol is neither hydrolysed nor absorbed intact by the human small intestine.' Further studies have shown that a substantial proportion of orally ingested lactitol is metabolised in vivo and the estimated caloric value of this sugar has been found to be approximately $2-3 \mathrm{kcal} / \mathrm{g}$ (Grimble et al, unpublished data). The disparity between the results of small intestinal perfusion experiments and the in vivo caloric utilisation studies suggested that the colon was the major site of lactitol metabolism. As lactitol also acts as an osmotic cathartic agent, ${ }^{4}$ we wondered whether this sugar might have a place in the treatment of hepatic encephalopathy. The results of the in vitro culture experiments clearly show that human faecal bacteria, under anaerobic conditions utilise lactitol as an energy substrate and that it was the release of volatile fatty acids that lowered the $\mathrm{pH}$ of the reaction mixture. Lactitol was metabolised in a similar manner to lactulose with acetic acid being the predominant volatile fatty acid produced in both cases. There are no published studies to compare our data of in vitro lactitol metabolism by colonic bacteria. A previous study of lactulose metabolism by colonic bacteria, however, suggested that lactic acid was the predominant metabolite produced." This study, however, was carried out using pure cultures of different species of faecal bacteria and not the mixtures of species that are found in the faeces.

The similarity of handling of lactulose and lactitol by human faecal organisms in our in vitro culture system prompted us to compare the effects of the two sugars on the luminal $\mathrm{pH}$ of the terminal ileum, colon, rectum as well as faecal $\mathrm{pH}$ in vivo. The $\mathrm{pH}$ profiles of the terminal ileum, and colon were found to be very similar to those reported by Bown et al who used the same experimental technique.? We have confirmed that lactulose when ingested in sufficient doses to produce two to four semi-formed motions a day lowers the $\mathrm{pH}$ of the right colon and no significant changes being noted in $\mathrm{pH}$ in the other regions of the colon, terminal ileum or faeces. The present findings show that lactitol has an exactly similar effect to that of lactulose on colonic $\mathrm{pH}$.

Table 1 Concentration of volatile fatty acids (mmol/l) produced after $24 \mathrm{~h}$ faecal incubation

\begin{tabular}{llc}
\hline & Lactitol & Lactulose \\
\hline Acetic acid & $40 \pm 13$ & $74 \pm 22$ \\
Propionic acid & $13 \pm 4$ & $15 \pm 6$ \\
Butyric acid & $23 \pm 16$ & $2 \pm 1$ \\
Lactic acid & $1 \pm 1$ & $2 \pm 1$ \\
\hline
\end{tabular}

$($ Mean $\pm S D, n=5)$. 
Table 2 Effect of lactulose and lactitol on pH of terminal ileum, colon and faeces

\begin{tabular}{|c|c|c|c|c|c|c|}
\hline & $n$ & Terminal ileum & Right colon & Left colon & Rectum & Faeces \\
\hline Basal & 6 & $7 \cdot 51 \pm 0 \cdot 37$ & $6.51 \pm\left(0.48^{*}\right.$ & $6 \cdot 33 \pm 0 \cdot 72$ & $6.53 \pm 0.69$ & $6 \cdot(1) \pm 0(0 \cdot 31$ \\
\hline Lactulose & 6 & $7 \cdot 23 \pm 0 \cdot 44$ & $5 \cdot 18 \pm(0 \cdot 82 \dagger$ & $5 \cdot 67 \pm 1 \cdot 03$ & $5.93 \pm 1.40$ & $5.72 \pm 1.67$ \\
\hline Lactitol & 6 & $7 \cdot(1) 8 \pm 0 \cdot 41$ & $5 \cdot 63 \pm 0.54 \ddagger$ & $6 \cdot 12 \pm 0 \cdot 63$ & $6 \cdot 58 \pm 0 \cdot 40$ & $6.54 \pm 0.46$ \\
\hline Lactulose + ncomycin & 3 & $7 \cdot 3 \pm 0.41$ & $6.4 \pm 0.96$ & $6.4 \pm 0.6$ & $6 \cdot 2 \pm 0 \cdot 4$ & \\
\hline
\end{tabular}

${ }^{*}$ Terminal ileum vs right colon $\mathrm{p}<0 \cdot()(0)$; †Basal vs lactulose $\mathrm{p}<() \cdot() 1 ; \ddagger$ Basal $v s$ lactitol $\mathrm{p}<() \cdot() 5$. Values are mean $\pm \mathrm{SD}$.

There are a number of explanations as to why the change in luminal $\mathrm{pH}$ induced by the two sugars occurs only in the right side of the colon. Firstly the luminal concentration of unabsorbed sugars will be high in the proximal colon. Therefore it is likely to be the major site of bacterial fermentation, producing maximum concentration of volatile fatty acids and consequently lowering the $\mathrm{pH}$. Secondly, the volatile fatty acids are avidly absorbed from the colonic mucosa, ${ }^{1213}$ so that their effect on luminal $\mathrm{pH}$ will diminish as luminal contents move distally. Finally it is known that bicarbonate ions are secreted into the lumen of the colon against both chemical and electrical gradients ${ }^{614}$ which will neutralise the acid.

The exact mechanisms whereby lactulose exerts its beneficial effect on hepatic encephalopathy are not fully understood. Available evidence suggests that lactulose acts by influencing the ammonia metabolism in the intestine. ${ }^{16-19}$ Ammonia is absorbed by non-ionic diffusion ${ }^{15}$ and it has been suggested that ammonia absorption is reduced as a consequence of conversion of ammonia to the ionised form in acid media. ${ }^{16}$ Such an explanation appears to be supported by studies that have measured ammonia concentrations in portal vein radicals during acidification of colon. ${ }^{17}$ Studies on ammonia loss in the faeces, however, have not shown the expected increase. ${ }^{2121}$ Vince et al ${ }^{1 \mathrm{x}}$ claim that net ammonia production is decreased after ingestion of unabsorbed sugar, firstly by facilitating growth of anaerobic bacteria and incorporating ammonia into bacterial proteins and secondly lowering the $\mathrm{pH}$ will inhibit the growth of proteolytic organisms. ${ }^{22}$ Finally it has been suggested that the cathartic effect of lactulose may serve to both reduced ammonia production and absorption. Whatever may be the mechanism whereby lactulose exerts its beneficial effect on hepatic encephalopathy, the present in vitro and in vivo studies show that lactitol is handled in the colon in a strikingly similar fashion to lactulose. Lactitol has superior taste properties and it is tolerated better by patients. ${ }^{5}$ We would therefore suggest that this sugar has potential as an alternative to lactulose in the treatment of hepatic encephalopathy.

The combination of lactulose and neomycin is often used in the treatment of hepatic encephalo- pathy on the basis presumably that the combination of the two is superior to using either drug alone. Although there are several studies showing that lactulose and neomycin when used on their own are equally effective in the treatment of hepatic encephalopathy, ${ }^{142.25}$ there are no controlled clinical trials showing that combination therapy is superior to the use of either drug on its own.' During the course of the present study we took the opportunity of examining the effect of neomycin on the colonic metabolism of lactulose both in vitro and in vivo. The findings show that neomycin inhibits the bacterial metabolism of lactulose in vitro and negates the effect of lactulose on right sided colonic $\mathrm{pH}$. Our findings therefore not only question the validity of combination therapy in hepatic encephalopathy, but raise the distinct possibility that neomycin might actually inhibit the beneficial effect of lactulose in this condition.

We thank Dr F Ahmad and Dr D A McSwiggan for culturing the samples; Dr G K Grimble and Mr M West for measuring the volatile fatty acids.

\section{References}

1 Conn HO, Lieberthal MM. The hepatic coma syndromes and lactulose. Baltimore: Williams and Wilkins, 1979.

2 Elkington SG. Lactulose. Gut 1970; 11: 1043-8.

3 Van Velthuijsen JA. Food additives derived from lactose; lactitol and lactitol palmitate. J Agric Food Chem 1979; 27: 680-6.

4 Patil DH, Grimble GK, Silk DBA. Intestinal absorption and laxative threshold of lactitol - a new hydrogenated derivative of lactose. [Abstract]. Gut 1985; 26: A1114.

5 Lanthier PL, Morgan MY. Lactitol in the treatment of chronic hepatic encephalopathy: an open comparison with lactulose. Gut 1985; 26: 415-20.

6 Giller J, Phillips SF. Electrolyte absorption and secretion in human colon. Am J Dig Dis 1972; 17: 1003-11.

7 Bown RL, Gibson JA, Sladen GE, Hicks B, Dawson AM. Effects of lactulose and other laxatives on ileal and colonic $\mathrm{pH}$ as measured by radiotelemetry device. Gut 1974; 15: 999-10(04.

8 Roediger WEW, Moore A. Effect of short chain fatty acid on sodium absorption in isolated human colon perfused through the vascular bed. Dig Dis Sci 1981; 26: $100-6$. 
9 Noll F. L-(+)-Lactate. Determination with LDH, GPT and NAD. Bergmeyer HU, ed. Method of enzymatic analysis. 2nd ed. New York and London: Weinheim and Academic Press Inc. 1974: 1475.

10 Meldrum SJ. Watson BW, Riddle HC, Bown RL, Sladen GE. pH profile of gut as measured by radiotelemetry capsule. Br Med J 1972; 2: 104-6.

11 Hoffman K. Mossel DAA, Korus W, Van de Kamer JH. Untersuchungen uber die Wirkungsweise der lactose (B galactosido-fructose) im Ddarm. Klin Wochenschr 1964; 42: 126-30.

12 McNeil NI, Cummings JH, James WPT. Short chain fatty acid absorption by the human large intestine. Gut 1978; 19: 819-22.

13 Ruppin H, Barr-Meir S, Soergel KH, Wood CM, Schmitt MG. Absorption of short chain fatty acids in the colon. Gastroenterology 1980; 78: 1500-7.

14 Bown RL. Sladen GE, Rousseau B, Gibson JA, Clark ML, Dawson AM. A study of water and electrolyte transport by the excluded human colon. Clin Sci 1972; 43: 891-902.

15 Summerskill WHJ, Asyogi F, Evans WD. Ammonia in the upper gastrointestinal tract of man: Quantitations and relationships. Gut 1966; 7: 497-501.

16 Cartell PD, Moore EW. Ammonia absorption from the human colon: the role of non-ionic diffusion. Clin Res 1968; 16: 528-32.

17 Birchen J, Hoemmerli HP, Trabert E, Largiacker F, Mocettii $T$. The mechanism of action of lactulose in portal-systemic encephalopathy. Non-ionic diffusion of ammonia in the canine colon. Rev Fr Stud Clin Biol 1971; 16: 352-7.

18 Vince A, Killingley M, Wrong OM. Effect of lactulose on ammonia production in a faecal incubation system. Gastroenterology 1978; 74: 544-9.

19 Elkington SG, Flock MH, Conn HO. Lactulose in the treatment of chronic portal systemic encephalopathy. A double-blind clinical trial. $N$ Engl J Med 1969; 281: 408-12.

20 Zeeger R, Drinkwater JE, Fenton JCB, Vince A, Dawson AM. Some observations on the effects of treatment with lactulose with chronic hepatic encephalopathy. QJ Med 1970; 39: 245-63.

21 Agostin L, Down PF, Murison J, Wrong OM. Faecal ammonia and $\mathrm{pH}$ during lactulose administration in man: Comparison with other cathartics. Gut 1972; 13: 859-66.

22 Vince A, Zeeger R, Drinkwater JE, O'Grady F, Dawson AM. The effect of lactulose on the faecal flora of patients with hepatic encephalopathy. J Med Microbiol 1974; 7: 163-8.

23 Bircher J, Hoemmerli UP, Siollo-Lavizzari G. Treatment of chronic portal systemic encephalopathy with lactulose. Am J Med 1971; 51: 148-59.

24 Conn HO, Leevy CM, Vlaliceria ZR, et al. Comparison of lactulose and neomycin in the treatment of chronic portal systemic encephalopathy. Gastroenterology 1977; 4: 573-82.

25 Fung WP, Khoo OT. Lactulose in the treatment of acute and chronic hepatic encephalopathy. Singapore Med J 1971; 12: 176-80. 